\title{
Guaranteed Ride Home Programs: A Study of Program Characteristics, Utilization, and Cost
}

\author{
William B. Menczer \\ Federal Transit Administration
}

\begin{abstract}
Guaranteed ride home programs play an important role in increasing public transportation ridership by providing a good reason to separate commuters from their single occupancy vehicles. Since they are inexpensive insurance policies, these programs provide a cost-effective way for a commuter to leave work in the event of a personal or family emergency or unexpected overtime. Research results show that usage rates and costs are quite low. As a possible incentive for commuters to leave their cars at home, these findings may make these programs attractive to communities that want to reduce congestion by increasing public transportation use. The research includes an examination of 55 such programs that serve the top 150 transit agencies in the United States.
\end{abstract}

\section{Introduction and Methodology}

As part of its effort to increase transit ridership and reduce congestion nationwide, the Federal Transit Administration (FTA) conducted research on guaranteed ride home $(\mathrm{GRH})$ programs that served 150 of the largest transit agencies in the United States. The overall goals of the research were to identify and describe key elements of the programs and performance measures to determine their use and cost effectiveness. The results of the research are intended to be used to convince communi- 
ties to adopt such programs where they presently do not exist and where they may help improve public transportation ridership.

According to a survey (Haas 2005) conducted on behalf of FTA by the Mineta Transportation Institute, 63 of the 150 largest transit agencies are covered by GRH programs. Of the 63 programs identified in the Mineta study, the study reported here is based on a review of 47 programs where complete data could be obtained. Data were also obtained for an additional 8 programs not included in the Mineta study that were in the top 150 largest transit agency list. A total of $55 \mathrm{GRH}$ programs were reviewed. The current study includes programs sponsored by transportation management associations (TMA), metropolitan planning organizations (MPO), municipal governments, and business associations.

Table 1 contains a complete list of organizations contacted over the course of conducting this study (see pages 146-148).

\section{Defining "Guaranteed Ride Home"}

Guaranteed Ride Home programs, also referred to as "emergency ride home" programs, are often described as an economical form of insurance. It reassures those commuters who do not drive alone that they have a timely and inexpensive way to leave work in the event of a personal or family emergency, illness, or unexpected employment-related delay, such as unscheduled overtime. These commuters include transit users, carpoolers, vanpoolers, pedestrians, and bicyclists (and in Santa Cruz Metro Transit District, roller bladers).

The purpose of the program is to increase transit use and ridesharing by removing the barrier of not having access to transportation in the event of an emergency. This lack of access prevents many from foregoing single occupant vehicle (SOV) travel to work.

\section{Eligibility}

Most GRH programs surveyed require that employees use alternative commuter modes such as public transportation, carpool, vanpool, walking, or biking for a minimum number of times per week. Tucson is an exception since walkers and bicyclists are not covered by the GRH program. In Monterey, California, employees must use alternate modes to commute to work at least once a week, while Sacramento requires three times a week, and Volusia County, Florida, four times a week. Other GRH programs require that the employee use an alternate commute 
mode on the day that a GRH is requested, such as Lane District Transit in Eugene, Oregon, and Clark County Transportation in Vancouver, Washington.

As shown in Figure 1, the majority of sponsors (54\%) require that to qualify for GRH benefits, commuters must travel using transit, van or carpools, walking, or bicycling. Twenty-two percent did not include walking or bicycling while 20 percent only covered the use of public transportation to the exclusion of all other modes in order for commuters to qualify for GRH benefits.

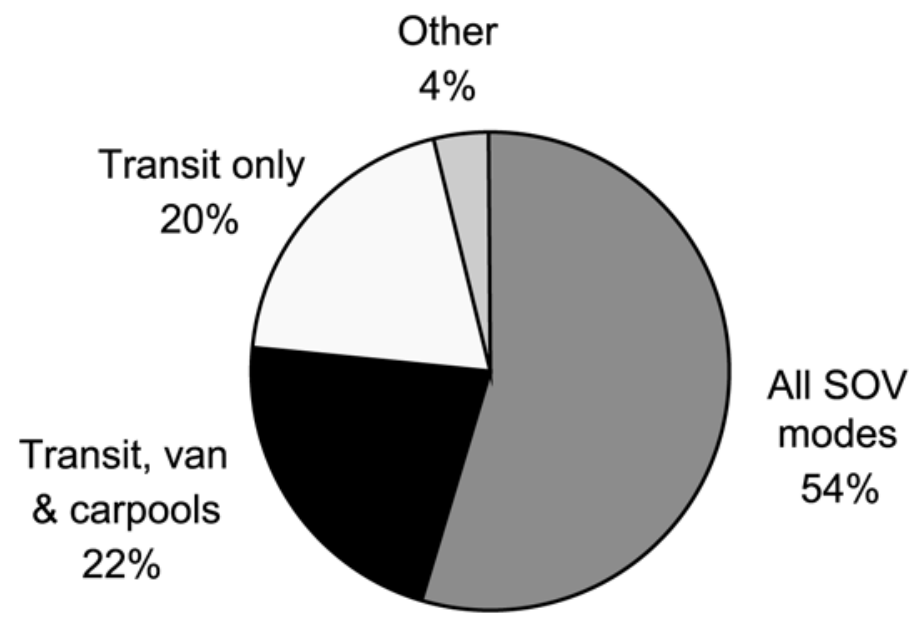

\section{Figure 1. Distribution of Non-SOV Modes Required for GRH Qualification}

\section{GRH Transportation Mode}

Most GRH programs have agreements with taxi companies, rental car companies, or both to provide service. Depending on the distance the employee must travel, some employees are allowed to rent cars, use employer vehicles, or be driven by another employee. The Transit Authority of Northern Kentucky provides rides only by agency road supervisors instead of rental cars or taxis. Central New York RTA in Syracuse, Niagara Frontier in Buffalo, Greater Cleveland, and Metro Tulsa Transit allow the use of either taxis or transit agency vehicles driven by agency supervisors. Madison Metro permits use of either taxis or employer fleet vehicles driven by the employee. San Francisco is the only GRH program that allows the use of a car-sharing company, City Car Share. 
As shown in Figure 2, a large majority of sponsors chose to offer a GRH only by taxi $(60 \%)$, followed by taxi or rental car (27\%). Transit agency vehicles are used either exclusively or in conjunction with taxis by 13 percent ( $9 \%$ with taxis and $4 \%$ exclusively agency-provided rides).

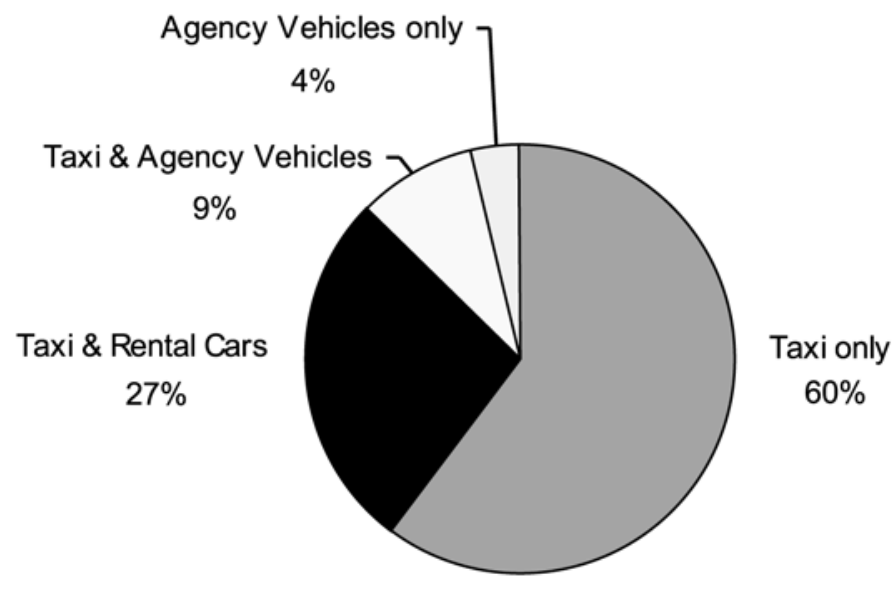

\section{Figure 2. Distribution of GRH Transportation Mode Allowed of $\mathbf{5 5}$ Transit Agencies in 2005}

Public transportation is often an integral part of a flexible, low-cost GRH program. GRH programs in areas with extensive transit systems often incorporate transit into their program design. Metropolitan Washington Council of Government's program in Washington, D.C. uses public transportation as one mode to get a commuter home quickly with minimal cost. When a commuter calls to request a ride, he or she may be instructed to take Metrorail or Metrobus to a distant station where a taxi will be waiting to complete the ride. Programs in Boston, Minneapolis/St. Paul, New York City, and Wilmington (Delaware) only approve an emergency ride for a transit rider when no transit service is available within 30 to 60 minutes.

Public transportation offers the potential to reduce the provider's cost of an emergency ride, but it may not serve every commuter's needs when a bona fide emergency occurs. Commuters who carpool or vanpool long distances or use transit periodically, particularly express buses and commuter rail, require GRH 
programs that supplement transit with more flexible and responsive services such as taxicabs or rental cars.

\section{Payment}

The two main methods of payment for the GRH program are vouchers issued to employees and reimbursement for direct payment by the employee to the vendor. With vouchers, only certain taxi companies can be used, which are arranged in advance by the program administrator. Vouchers may be used in some programs for rental cars. In the event of employee payment to the vendor, the employee may be restricted to choices of taxis and rental car companies. Vouchers are distributed to employees either when they register for the program or when requested from the on-site employee transportation coordinator (ETC) on the day of need.

As shown in Figure 3, the majority of sponsors (56\%) pay for the GRH costs through the use of vouchers, followed in equal portions (22\% each) by either direct payment by the sponsor to the transportation provider or by reimbursement to the traveler.

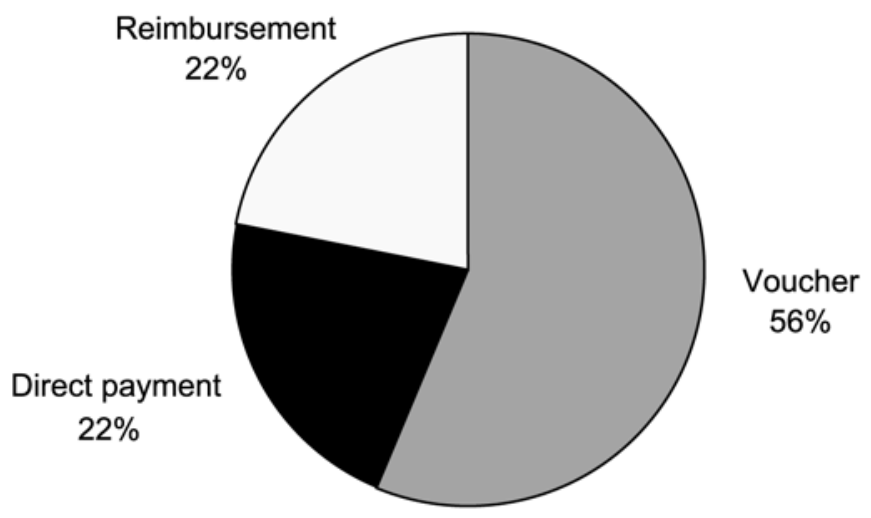

Figure 3. Distribution of GRH Payment Methods

\section{Destinations}

Most programs allow employees to travel to destinations other than their homes, such as a park-and-ride lot, an educational facility to pick up a dependant, a pharmacy to obtain a prescription, or a hospital to check on a family member. Program rules normally specify where and how many intermediate stops are permitted. For 
example, Sacramento allows 10-minute intermediate stops to a park-and-ride lot, home, or to a hospital. Lane Transit in Eugene allows a 15-minute stop to a location directly related to the emergency. Programs in Miami, Orlando, San Francisco, and Seattle permit multiple intermediate stops, while those in Kansas City, San Antonio, and Santa Cruz each allow only one stop.

\section{Distance and Cost}

Most programs specify limits on either the distance to be traveled or the amount of payment that may be incurred. Some restrict travel within specific geographic boundaries, such as within the city or county limits. For example, in San Antonio, taxi rides up to 60 miles within Bexar County are permitted. Clark County limits cab rides to 50 miles. Most programs permit taxi cab use for rides less than 20 miles or when the commuter is ill, does not have a license, or does not meet other requirements of using a rental car. An exception to the 20-mile rule is found in Denver where the program allows taxi rides up to 100 miles one way. San Francisco permits the use of City Car Share vehicles for trips up to 200 miles.

\section{Program Rules}

To minimize abuse of the program, most (89\%) place restrictions on the number of rides that may be claimed per a specified period. This study found the limits range from two per year to no limit at all. Those offering only two per year, representing 7 percent of those surveyed, are Hartford, Las Vegas, Phoenix, and Santa Cruz. Denver, Greater Richmond, Kitsap Transit, San Mateo, Santa Clara Valley, and Syracuse have no limits on the number of GRH requests a commuter can make either monthly or annually.

As shown in Figure 4, the most common GRH limit is four rides per year (offered by $37 \%$ of the transit agencies), followed by six rides per year (offered by $17 \%$ of the transit agencies). Eleven percent of the agencies surveyed have no annual limit on the number of rides permitted.

Most GRH programs do not place dollar limits on the cost of the trips, but those that do range from per-trip lows of $\$ 25$ in Minneapolis, $\$ 30$ in Oklahoma City, and $\$ 35$ in Cleveland, to highs of $\$ 100$ in Tampa, and $\$ 200$ in San Francisco (capped at $\$ 700$ per year).

Some programs require commuters to make copayments. These include San Diego (\$3), Central Ohio Transit Authority (10\% of the fare), Southwest Ohio Regional Transit (20\% of the fare), Dallas ( $\$ 10$ for vanpool users), Fort Worth $(\$ 5)$, and Richmond ( $\$ 5$ after the third claim). Phoenix provides the first ride free; subsequent 


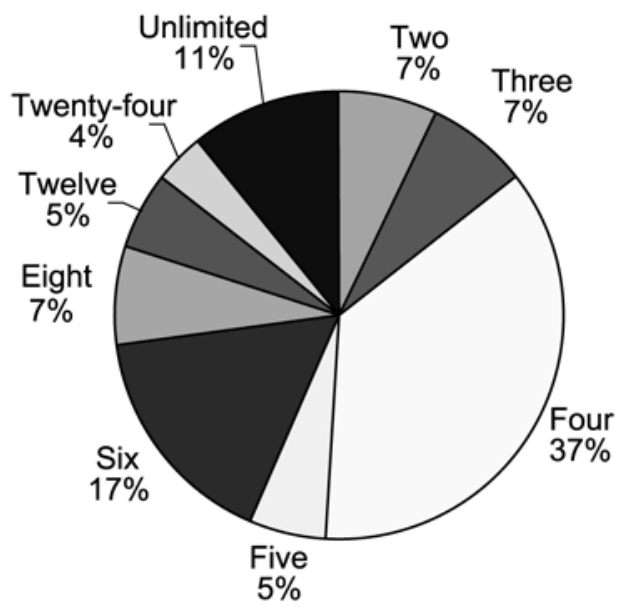

\section{Figure 4. Distribution of Maximum Annual Rides Allowed among GRH Agencies in 2005}

rides cost the user 50 percent of the total cost. Saint Louis requires a 20 percent copayment on rides costing up to $\$ 40$ and requires the user to pay 100 percent of the costs in excess of $\$ 40$.

Registration fees paid by commuters could constitute an impediment for the successful implementation of a GRH program. For example, the \$15 annual fee at San Antonio's VIA Metro entitles commuters to receive four vouchers for the year. Only two commuters are registered for this program despite an extensive marketing and outreach program. Austin's Capital Metro Transit imposes a \$5 annual fee for a GRH program covering vanpool and express bus riders. They receive up to four taxi rides per year, each for a maximum cost of $\$ 48.50$. Only 152 commuters are registered in this program.

Trip purposes are clearly defined in almost all programs. Common purposes include a personal or family illness or emergency, unscheduled overtime approved by a supervisor, and the unavailability of a rideshare partner due to his or her having to leave early or to stay late unexpectedly. Common prohibitions include preplanned events such medical or dental appointments, scheduled overtime, business-related travel, public transportation breakdowns, on-the-job injuries, claims on days when the commuter did not use an alternative to SOV travel, or 
severe weather. Unusual prohibitions include major area disasters in Bremerton, Washington, and employment terminations or layoffs in Tacoma, Washington.

\section{Cost and Use of GRH Programs}

$\mathrm{GRH}$ programs generally require minimal funding and staff time to operate. As indicated in Table 2, the cost of GRH claims is not significant. Comparisons of $\mathrm{GRH}$ program costs with overall rideshare program costs were not possible since complete financial data was not available from all programs studied.

\section{Table 2. Overall Cost of GRH Programs Surveyed}

\begin{tabular}{|l|l|l|l|l|l|}
\hline $\begin{array}{l}\text { Mean } \\
\text { Cost per } \\
\text { Claim }\end{array}$ & $\begin{array}{l}\text { Median } \\
\text { Cost per } \\
\text { Claim }\end{array}$ & $\begin{array}{l}\text { Range of Cost } \\
\text { per Claim }\end{array}$ & $\begin{array}{l}\text { Mean } \\
\text { Annual } \\
\text { Cost per } \\
\text { Registrant }\end{array}$ & $\begin{array}{l}\text { Median } \\
\text { Annual } \\
\text { Cost per } \\
\text { Registrant }\end{array}$ & $\begin{array}{l}\text { Range of } \\
\text { Annual Cost } \\
\text { per } \\
\text { Registrant }\end{array}$ \\
\hline$\$ 36.95$ & $\$ 29.96$ & $\$ 0-\$ 114.08$ & $\$ 1.69$ & $\$ .35$ & $\$ 0-\$ 15.78$ \\
\hline
\end{tabular}

The average cost per claim, in this survey, was $\$ 36.95$, with a median cost of $\$ 29.96$ and a range of no cost to $\$ 114.08$. Those with average costs per claim of less than \$20 were Albuquerque, Greater Richmond Minneapolis, Lane Transit, Madison Metro, and San Francisco. Grand Rapids, Monterey, San Antonio, and Volusia County (Florida) reported no claims during their most recent fiscal year. Syracuse, the Transit Authority of Northern Kentucky, and Tulsa used agency vehicles for rides home and therefore recorded no costs incurred during their last fiscal year. Those with average costs per claim over $\$ 75$ were Alameda, Birmingham, Boston Commuter Works, San Mateo, and Ventura. In 1993, a typical trip cost was estimated to be $\$ 30$ and average cost per employee was under $\$ 5$ per year (Comsis Corporation 1994). These costs are equivalent to $\$ 38.20$ and $\$ 6.37$ in 2005 dollars, respectively (Federal Reserve Bank of Saint Louis 2005), which are both higher than those found in this study.

Figure 5 shows the distribution of average (mean) costs per ride. It indicates that the most common cost categories are $\$ 20$ to $\$ 30$ (25\% of agencies surveyed) and $\$ 30$ to $\$ 40$ (20\%). No cost (13\%) and from $\$ 10$ to $\$ 20$ (11\%) represent the next most common cost categories. 


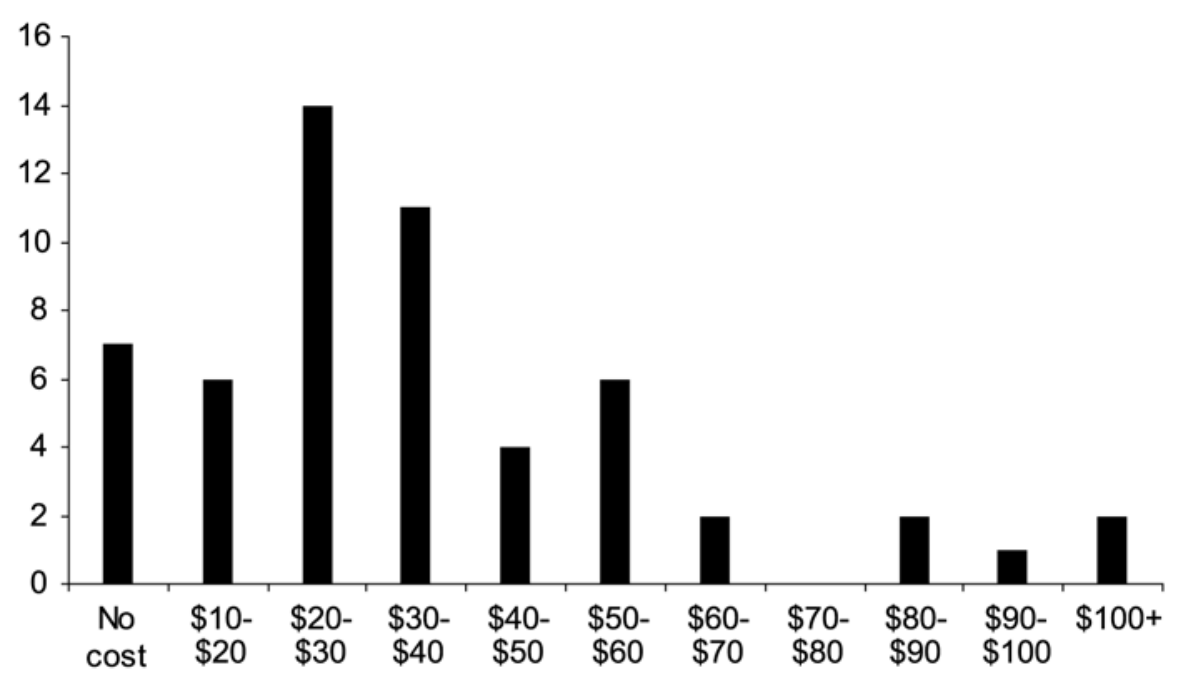

Figure 5. Distribution of Average Cost per Claim in 2005

The average (mean) annual cost per registered commuter was very low at only $\$ 1.69$ with a median cost of only $\$ .35$, and a range of no cost to $\$ 15.78$. Those with average costs per commuter of less than $\$ 0.30$ were Las Vegas, Pierce County, San Francisco (all at \$0.02), Albuquerque, Central Ohio, Clark County, Dallas, Delaware, Kansas City, Lane Transit, Milwaukee, River City, Rochester, Sacramento, Saint Louis, Santa Clara, Santa Rosa, Southwest Ohio, Tucson, and Utah. Those with average costs per registered commuter of more than $\$ 10$ were Contra Costa at $\$ 13.16$ and Fort Worth at $\$ 15.78$.

Figure 6 shows the distribution of the average annual costs per registered commuter. It indicates that the most common cost categories are less than $\$ 1$ (44\% of agencies surveyed), $\$ 1$ to $\$ 2(18 \%)$, and no cost (13\%).

Figure 7 shows that there does not appear to be a correlation between average cost per ride and the size of the service area. It would be reasonable to assume that costs would rise with the size of the area served by the GRH. The data shows, however, that this is not the case. Service area sizes in this study range from 22 square miles in Alameda County to 3,940 square miles in Orlando. The majority of the service areas are less than 600 square miles. 


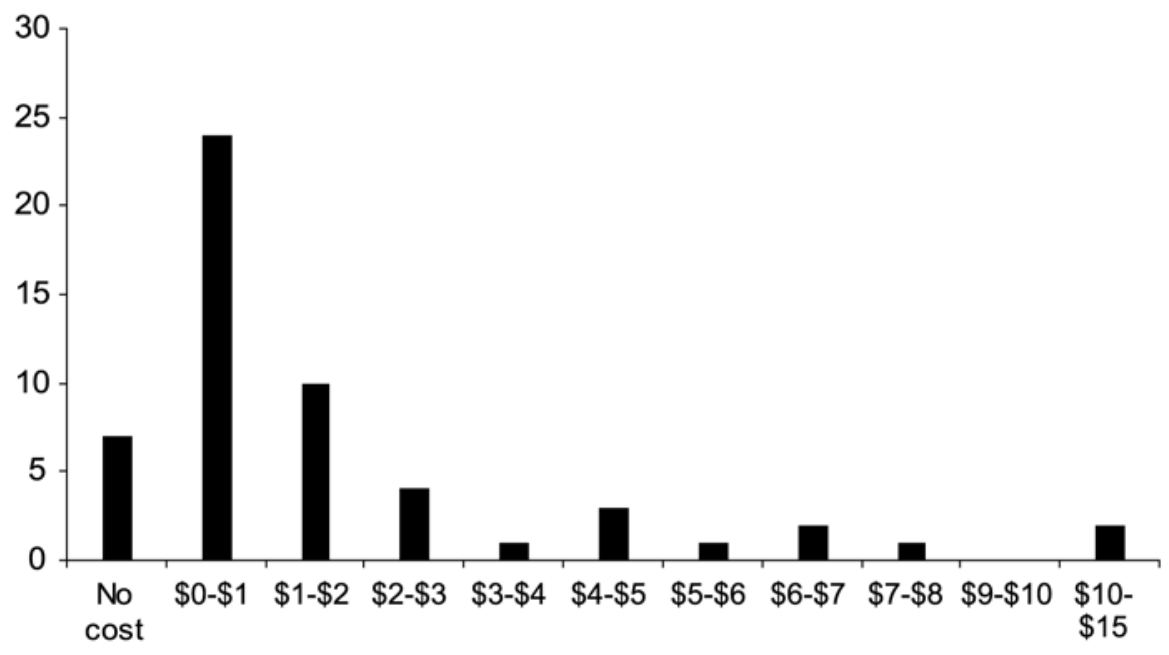

Figure 6. Distribution of Average Cost per Registrant in 2005

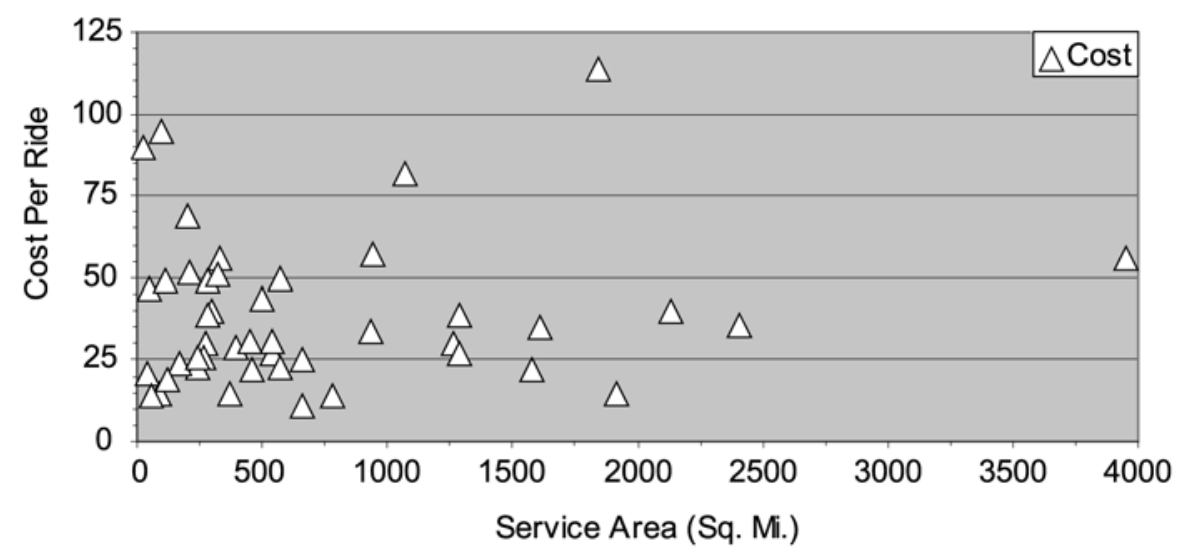

Figure 7. Correlation of Cost and Service Area

As indicated in Table 3, the overall use of GRH programs is not significant, as would be expected with any insurance program. The average use of the program in this survey, per registered commuter, was a very modest 4.57 percent, with a 
median use of 1.29 percent and a range from none to 30.87 percent. Those with usage rates of less than 1 percent during the last fiscal year were Cincinnati, Clark County, Columbus, Dallas, Delaware, Kansas City, Las Vegas, Milwaukee, Pierce County, River City, Sacramento, Saint Louis, San Francisco, Santa Clara, Santa Rosa, Tucson, and Utah. Those with usage rates more than 10 percent were Atlanta, Contra Costa, Fort Worth, Greater Richmond, Hillsborough, Miami, Minneapolis, Oklahoma City, Transit Authority of Northern Kentucky, and Washington, D.C.

\section{Table 3. Overall Use of GRH Programs Surveyed}

\begin{tabular}{|c|c|c|}
\hline $\begin{array}{c}\text { Mean Use per } \\
\text { Registrant }\end{array}$ & $\begin{array}{c}\text { Median Use per } \\
\text { Registrant }\end{array}$ & Range of Use per Registrant \\
\hline $4.57 \%$ & $1.29 \%$ & $0 \%$ to $30.87 \%$ \\
\hline
\end{tabular}

Figure 8 shows the distribution of the mean usage per registered GRH participant. The most common category is the average usage rate under 1 percent found among 31 percent of all agencies surveyed, followed by those over 10 percent, 1 to 2 percent, and those agencies with no usage.

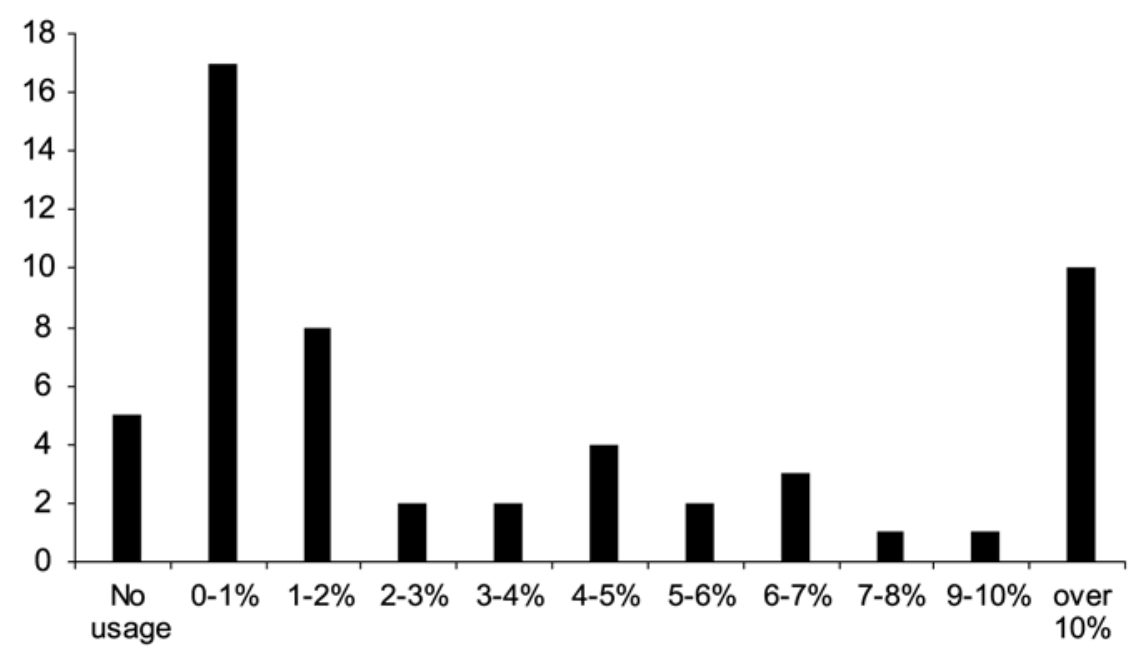

Figure 8. Distribution of Mean Usage per Registrant in 2005 
Figure 9 shows a negative correlation between average usage rates and the maximum number of rides allowed per year, but no statistically significant correlation. It would be reasonable to assume that usage would rise with the greater number of annual rides permitted. The data shows, however, that this is not the case. For the six agencies that permitted an unlimited number of rides per year, five agencies had usages rates under 6 percent. Greater Richmond Transit had a 26.11 percent usage rate. This high rate was due to geographic expansion of the program which attracted a large number of new registrants during the reporting year. According to the Richmond GRH program manager, new users in Richmond typically have higher claim rates in their first year until they become familiar with the program. Usage rates for the current fiscal year are considerably lower. For the two agencies with an annual limit of 24 , the usage rates were 1.47 percent and 6.67 percent.

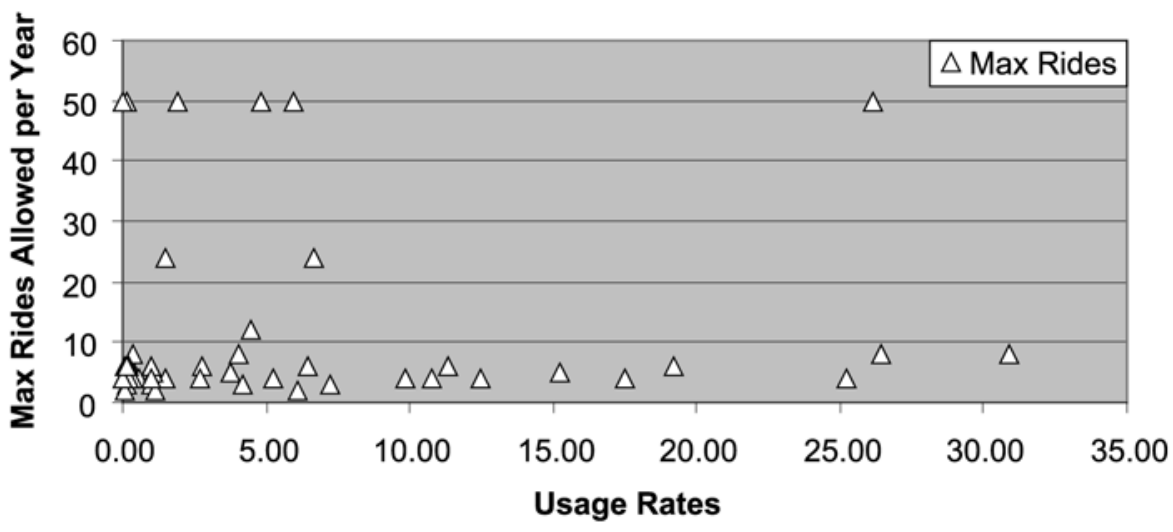

\section{Figure 9. Correlation of Usage with Maximum Number of Rides Permitted}

Figure 10 shows an apparent negative relationship between average usage rates and the size of the GRH service area. As the service areas of the GRH program decreases, the rates per registered user per year increases. As noted earlier, service area sizes in this study range from 22 square miles in Alameda County to 3,940 square miles in Orlando. The majority of the GRH programs surveyed serve areas that are less than 600 square miles in size. 


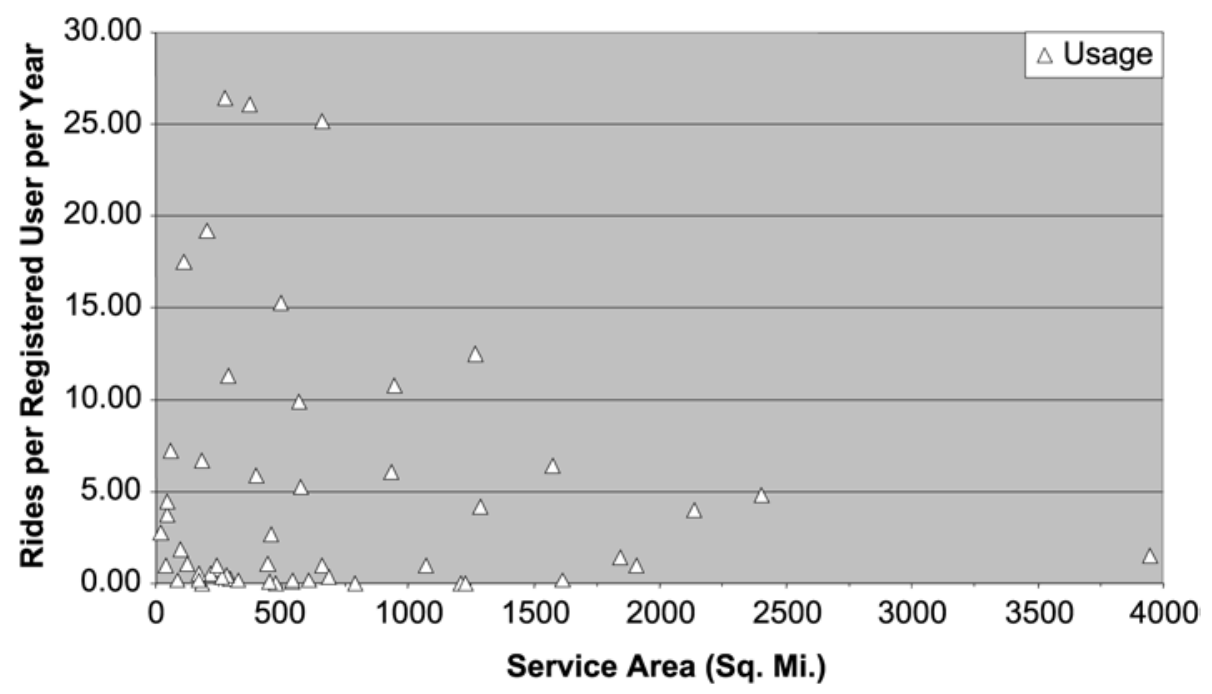

Figure 10. Correlation of Usage and Service Area

\section{Impact on SOV Commuting}

Most programs have anecdotal evidence from post-ride surveys and unsolicited commuter response regarding how offering GRH decreases SOV travel. These survey results show that offering GRH may contribute to some commuters shifting from driving alone to non-SOV commuting including public transportation.

In a 1999 survey of Tappan Zee (New York) express bus riders, 16 percent said they would definitely stop using the service without GRH.

A 2002 survey conducted by the Artery Business Committee in downtown Boston found that 9 percent of those responding to the survey switched from SOV commuting to an alternate mode of transportation due to the existence of a GRH program.

A 2002 survey of Haverstraw-Ossining Ferry riders in New York found 41 percent of those surveyed stated that the GRH was among the top reasons for taking the ferry instead of their previous mode of transportation. Four percent ranked GRH as their number one reason for taking the ferry. 
A 2003 study conducted for the Denver Regional Council of Governments found that a GRH program, at no cost to the user, would increase carpooling frequency by 17 percent for those who plan to join a carpool in the next year. Three percent of SOV commuters said they would carpool at least once a week if they found suitable partners and were covered by a GRH. The GRH would increase carpooling frequency for this group by 8 percent (Vantage Marketing Research 2003).

A program evaluation conducted in 2004 for the Alameda County Congestion Management Agency found that 47 percent of those surveyed would not use alternate modes of transportation without a GRH program. In 2003, the number was 41 percent (Nelson/Nygaard Consulting Associates 2005).

\section{Conclusion}

GRH program costs were found to be rather modest in this study. The average cost per claim of $\$ 36.95$ and average cost per registered participant of $\$ 1.69$ were quite low. Usage, comparable to other insurance programs, was equally low. Only an average of 4.57 percent of those registered in this study used the program during the most recent fiscal year. There did not appear to be a statistically significant correlation between average usage rates and the maximum number of rides permitted, between average cost and service area size, or between average usage and service area size. Therefore, agencies need not be parsimonious in setting the limit on the number of rides allowed per year for fear of high use and cost, or abuse.

There are more similarities than differences among the GRH programs surveyed in this study. Eligibility normally encompasses those who use alternative commuter modes and do not include SOV; the primary difference is in the number of days required for use of these modes. At least 60 percent of the programs use taxis to provide GRH services, which are often supplemented by rental cars. Payment for the service is either through reimbursement of the commuter or by the use of vouchers redeemable with specified providers. Most programs allow employees to travel to destinations other than their residences and many permit intermediate stops along the way. There is a large degree of consistency among the programs regarding the circumstances under which GRH can be provided and when it is not allowed. Most programs do not limit the cost of taxis or rental cars, and only some limit the total distance traveled. The vast majority of the programs limit the number of eligible claims per year, with a plurality allowing up to four rides per year. 
Although there are no recent national studies that assess the impact of these programs on SOV commuting, several local studies conducted in recent years indicate a positive impact on modal shift and on public transportation use.

Communities considering implementation of a GRH program should develop a written policy identifying how the program will serve them. The policy should show that emergency transportation will be fast, convenient, and at what cost, if any, to the user. Eligibility requirements, valid reasons for use of the service, registration requirements, and restrictions must all be addressed. The policy should identify the maximum number of trips permitted per year, any limitations on mileage, the transportation options available, and the maximum cost per trip. Requirements should not be overly restrictive to encourage maximum participation in the program. Some nonemergency trips should qualify for GRH to encourage more commuters to choose non-SOV modes. Potential users, which can be defined as all commuters, should be involved in the planning process to ensure a design that is most attractive to the largest number of commuters.

Every year, more communities realize that GRH programs may serve as an incentive for commuters to leave their cars at home and use public transportation and other non-SOV modes. This should continue to increase transit ridership and other non-SOV modes of commuting, and contribute to reduced levels of congestion. 


\begin{tabular}{|c|c|c|c|c|c|c|c|c|c|c|c|c|c|c|c|c|c|c|c|c|c|c|c|}
\hline 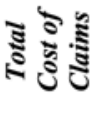 & & 空 & 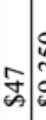 & 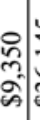 & 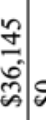 & \& & 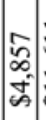 & $\overrightarrow{0}$ & & $\begin{array}{l}0 \\
\vdots \\
\vdots \\
\vdots \\
\leftrightarrow\end{array}$ & 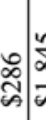 & 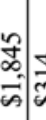 & 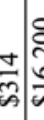 & 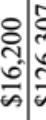 & \begin{tabular}{l}
$\infty$ \\
$\infty$ \\
\multirow{N}{*}{} \\
\multirow{\sim}{*}{}
\end{tabular} & în & 点 & ڤิ| & ભૂ & \& & $\mid \begin{array}{c}5 \\
\vdots \\
\vdots \\
a \\
\end{array}$ & 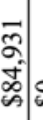 & \& \\
\hline 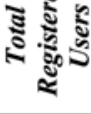 & 8 & సิ & $\vec{\beth}$ & $\begin{array}{l}\underset{N}{N} \\
\text { mis }\end{array}$ & ํํㄴ & 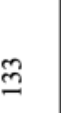 & 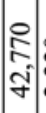 & సે & ही: & ㄱ. & 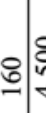 & 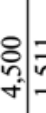 & $=$ & 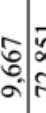 & : & $\mid \begin{array}{l}\overline{\hat{O}} \\
\hat{\mathrm{v}}\end{array}$ & त्र & 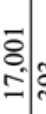 & ભૂ & $\widehat{b}$ & $\bar{a}$ & 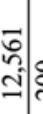 & હ્స \\
\hline 胥 & $m$ & $N$ & $\nabla$ & ○. & c. & 0 & (०). & $\nabla$ & $m:$ & & 큳 & $N$ & $+\lesssim$ & 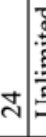 & N & 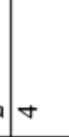 & + & ○. & + & $\nabla$ & $\infty$ & $n$ & F \\
\hline $\begin{array}{l}5 \\
5 \\
5 \\
5\end{array}$ & $\stackrel{\circ}{\circ}$ & ఫे & ○ุ & 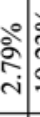 & ஸิ่ & 0 & ঐे & 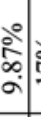 & 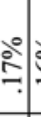 & 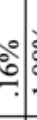 & 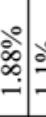 & ¿ْ & ลे & לें & $\frac{\circ}{6}$ & 家 & คిำ & : & i̊ & 0 & خे. & 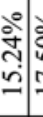 & مُ \\
\hline 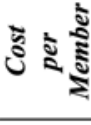 & $\begin{array}{l}\infty \\
\infty \\
\dot{\infty}\end{array}$ & के & $\frac{9}{4}$ & 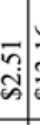 & $\frac{0}{\mathrm{c}}$ & 0 & $=$ & 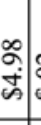 & 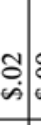 & sid & $\frac{2}{\dot{s}}$ & $\overrightarrow{0}$ & $\begin{array}{c}\overrightarrow{0} \\
\dot{\omega}\end{array}$ & 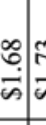 & 숑 & $\begin{array}{l}\infty \\
0 \\
0 \\
0\end{array}$ & શิ & $\begin{array}{c}n \\
\\
\\
\end{array}$ & $\begin{array}{l}\curvearrowright \\
\infty \\
\dot{\leftrightarrow}\end{array}$ & 0 & ڤ్ & 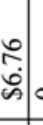 & 0 \\
\hline కั & 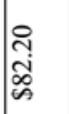 & 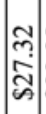 & $\begin{array}{l}\infty \\
\text { ñ. } \\
\\
\end{array}$ & ڤి. & $\begin{array}{ll}0 \\
+ \\
0 \\
0 \\
0 \\
0\end{array}$ & 0 & 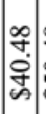 & \&. & $\begin{array}{l}\infty \\
\stackrel{\infty}{5} \\
\dot{\square}\end{array}$ & 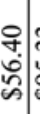 & 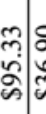 & 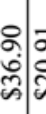 & $\bar{\sigma}$ & & ঠे & $\frac{a}{n}$ & 水 & 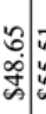 & $\begin{array}{l}\sqrt{n} \\
n \\
n \\
n\end{array}$ & 0 & $\begin{array}{l}\text { న. } \\
\text { స่ }\end{array}$ & के & \\
\hline 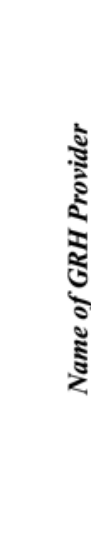 & 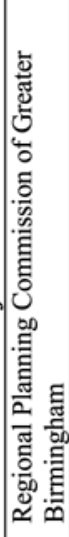 & 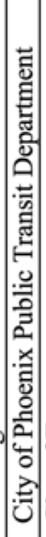 & 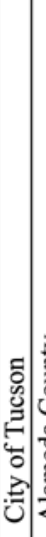 & 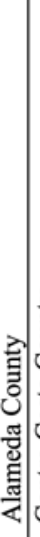 & | & 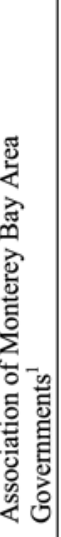 & 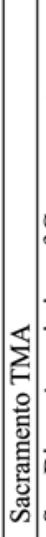 & 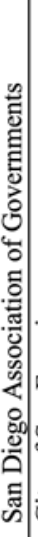 & 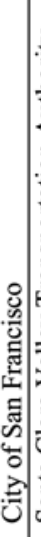 & 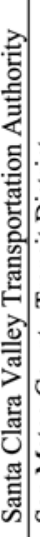 & 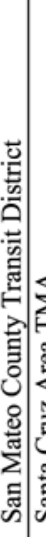 & 施 & 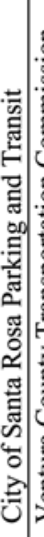 & 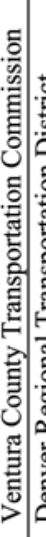 & 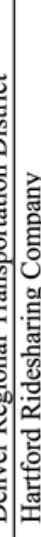 & 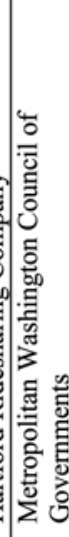 & $\mid$ & 苟 & 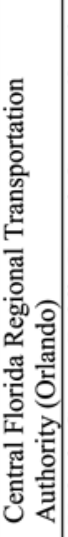 & 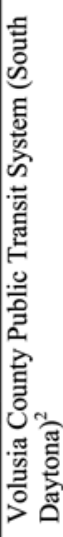 & 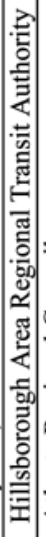 & 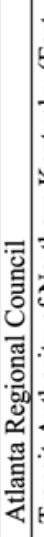 & 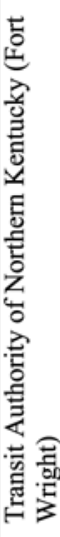 \\
\hline ฟัँ & $\frac{1}{4}$ & $\frac{N}{4}$ & 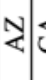 & & 0 & U & త & & & & 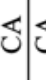 & & & తు & 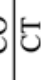 & Ua & 㭊 & 可边 & $\overrightarrow{|r|}$ & 至 & 실. & త্ & $\sqrt{2}$ \\
\hline
\end{tabular}




\begin{tabular}{|c|c|c|c|c|c|c|c|c|c|c|c|c|c|c|c|c|c|c|c|}
\hline ป气 & \& & 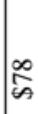 & $\begin{array}{l}\tilde{\infty} \\
\tilde{\infty} \\
\tilde{\kappa}\end{array}$ & 空 & \& & & & İ & $\frac{\infty}{\infty}$ & 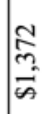 & $\frac{8}{\infty}$ & \& & $\frac{d}{\infty}$ & 考? & $\begin{array}{c}\infty \\
\text { L } \\
\text { in }\end{array}$ & ల్ల & & బ, & $\frac{\mathscr{N}}{\stackrel{n}{A}}$ \\
\hline 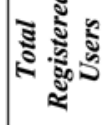 & స్. & $\mathscr{\sigma}$ & $\begin{array}{l}\tilde{N} \\
\infty \\
-\end{array}$ & নั & $\simeq$ & กิ| & ț & క. & : & ลू. & ৪্ণ & ¿̊ & ్ి & : & $\begin{array}{l}\text { స్ } \\
\text { తి }\end{array}$ & $\infty$ & & : 20 & $\stackrel{m}{\stackrel{m}{2}}$ \\
\hline 誌: & t & o & $\cong$ & $n$ & $\nabla$ & $\nabla$ & $\nabla \nabla$ & ton & $N$ & 0 & 0 & 畩 & $\nabla$ & + & $\nabla$ & \& & & $+\mid$ & $\infty$ \\
\hline : & مْ & 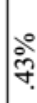 & 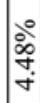 & 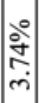 & & 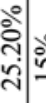 & ำ & مَ & : & 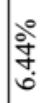 & $\varrho^{\circ}$ & 0 & लें & $\mid$ & & ִָ & & & :्ల \\
\hline
\end{tabular}

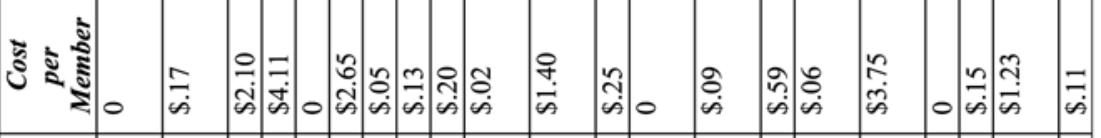

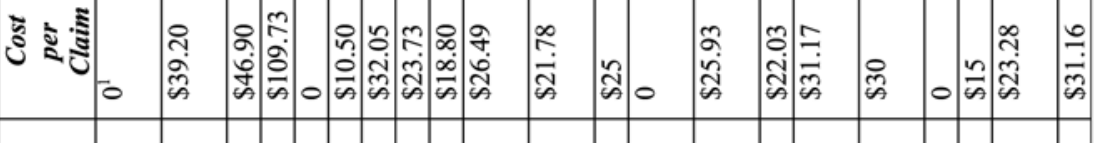

\begin{tabular}{|c|c|c|c|c|c|c|c|c|c|c|c|c|c|c|c|}
\hline 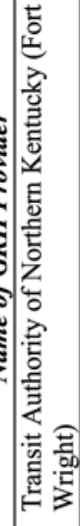 & 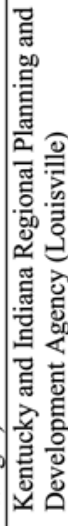 & \begin{tabular}{|c|c}
0 \\
0 \\
0 \\
0
\end{tabular} & 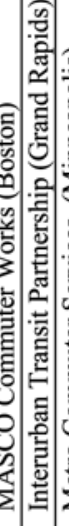 & 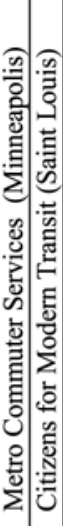 & \begin{tabular}{l|l}
3 & 0 \\
3 & 0 \\
0 \\
0
\end{tabular} & 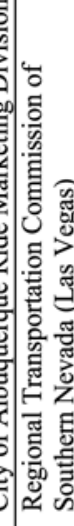 & 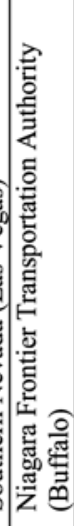 & 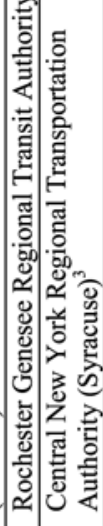 & 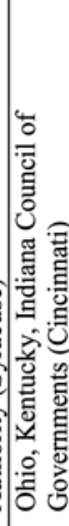 & & 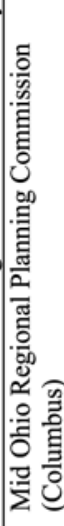 & 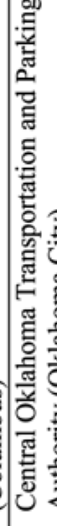 & $\frac{5}{5}$ & & 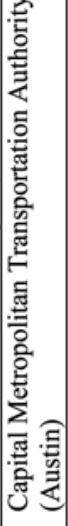 \\
\hline & & 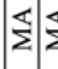 & $\Sigma|\Sigma|$ & $\sum \mid \stackrel{0}{\Sigma}$ & I0 & & z & そे| & 0 & & & & & & \\
\hline
\end{tabular}




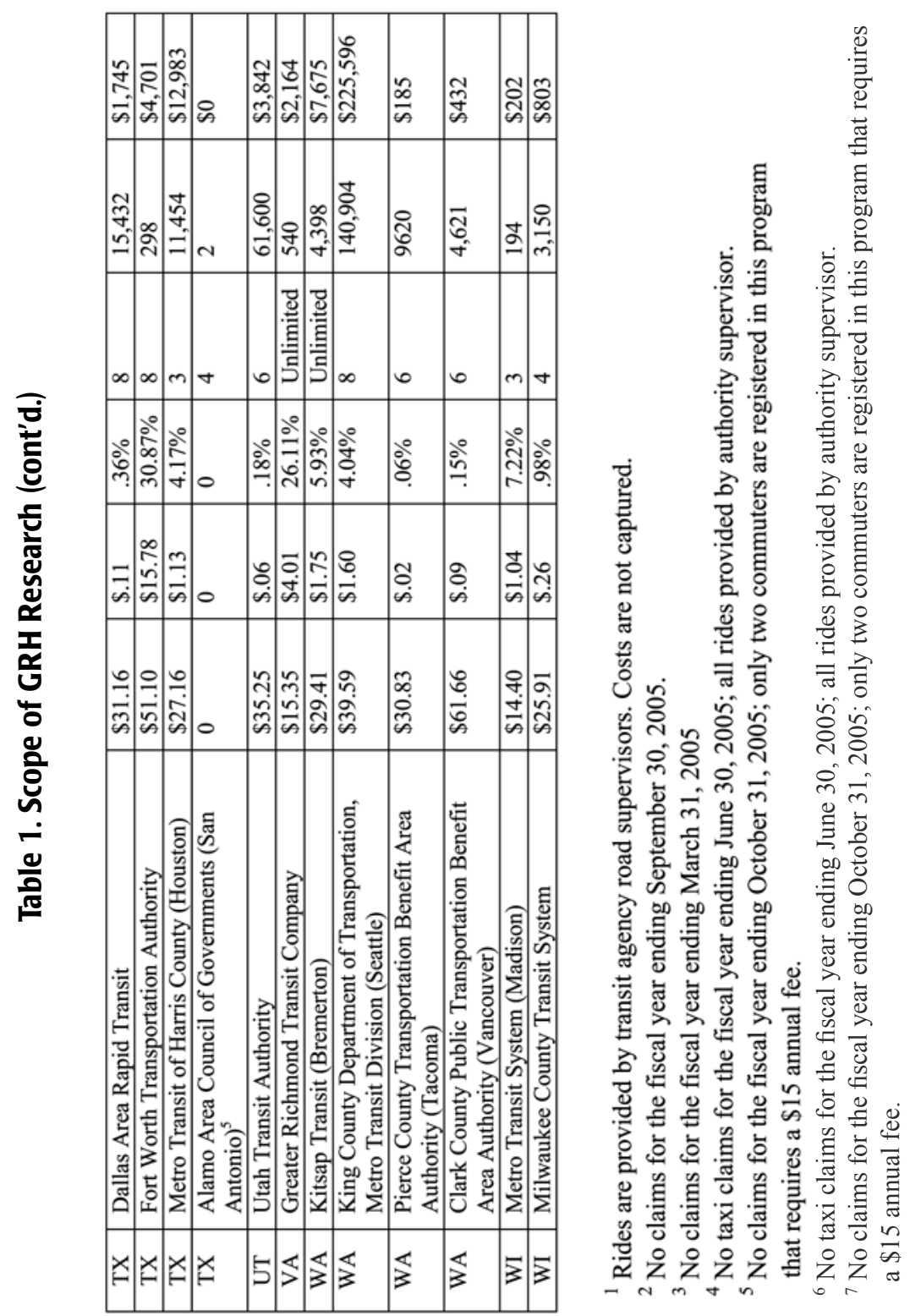




\section{References}

Comsis Corporation. 1994. A survey and analysis of employee responses to employer-sponsored trip reduction incentive programs. Sacramento, CA: California Air Resources Board.

Federal Reserve Bank of Saint Louis. 2005. Gross domestic product: Implicit price deflator.

Haas, Peter J. 2005. Ridership enhancement quick study. Washington, DC: Federal Transit Administration Report Number FTA-CA-26-7070-05.01.

Nelson/Nygaard Consulting Associates. 2005. Alameda County CMA guaranteed ride home program evaluation: Executive summary.

Vantage Marketing Research. 2003. Commuter transportation survey 2003. Denver, CO: Denver Regional Council of Governments RideArrangers.

\section{About the Author}

William B. MenCzer (William.Menczer@dot.gov) is the senior program analysis officer in the Office of Policy and Performance Management, Federal Transit Administration, U.S. Department of Transportation in Washington, DC. His previous management positions at FTA have included serving as the Acting Chief of the Performance Management Division, as the Director of the Office of Policy Development, and as the Director of the Office of Oversight. He received his Masters degree in public administration from the Maxwell School of Citizenship and Public Affairs at Syracuse University. His research has focused on internal and external factors that impact public transportation ridership, travel demand management, and qualified transportation fringe benefits. He has published numerous articles on these subjects in magazines, in international conference proceedings, and in the FTA website. 